\title{
THE CARDIOVASCULAR EFFECTS OF KETAMINE IN HYPOTENSIVE STATES
}

\author{
David H.W. Wong and Leonard C. Jenkins*
}

\section{INTRODUCTION}

BECAUSE of its apparent lack of effect on cardiovascular stability and its beneficial effects on the blood pressure, ketamine is generally believed to be a suitable anaesthetic agent for high risk patients and patients in shock. ${ }^{1-3}$ One clinical report stated that "the effect of ketamine on the patient in shock was quite dramatic." However, Virtue et al. ${ }^{5}$ found that ketamine $2.2 \mathrm{mg} / \mathrm{kg}$ raised the blood pressure in normovolaemic dogs but not in hypovolaemic dogs which had been bled 1/30th of the body weight.

The purpose of the present study was to examine the haemodynamic effects of ketamine in hypotensive states induced experimentally by blood volume depletion and by endotoxin treatment.

\section{Methods}

Cats were intubated after intramuscular injection of succinylcholine $20 \mathrm{mg}$, and then were ventilated with a Palmer respiratory pump (London, England) at a flow of 4 litres of nitrous oxide and 4 litres of oxygen per minute using a Sierra unidirectional valve. The $\mathrm{PaO}_{2}$ was maintained at 150 to 200 torr, $\mathrm{PacO}_{2} 26$ to 34 torr, and pH 7.35 to 7.45. Occasionally, sodium bicarbonate was used to correct a pre-existing metabolic acidosis. An electric warming pad was used to maintain the rectal temperature from $100^{\circ}$ to $102^{\circ} \mathrm{F}$.

The haemodynamic parameters that were monitored included the following (Figure 1):

1. Central venous pressure, using simple manometry with a catheter inserted into the right external jugular vein and advanced approximately $10 \mathrm{~cm}$ towards the heart.

2. Arterial blood pressure, mean blood pressure, and heart rate, measured from the right femoral artery, using a Statham strain-gauge (Hatorey, Puerto Rico), connected to a S.E. transducer/converter (Type SE 905, S.E. Laboratories, Feltham, England) and displayed on a S.E. ultra-violet recorder (Model 3006, S.E. Laboratories) with paper speed of $10 \mathrm{~mm}$ per second. The pressure was calibrated with a Tycos oscilloscope.

3. Cardiac output was measured by the dye-dilution technique. Indocyanine green (Cardio-Green ${ }^{\circledR}$, Hynson, Westcott \& Dunning, Inc., Baltimore, Maryland) was used at a concentration of $1.25 \mathrm{mg}$ per $\mathrm{ml} .0 .25 \mathrm{mg}(0.2 \mathrm{ml})$ of the dye was in-

'From the Department of Anaesthesia and Experimental Research Laboratory, Faculty of Medicine, University of British Columbia. 


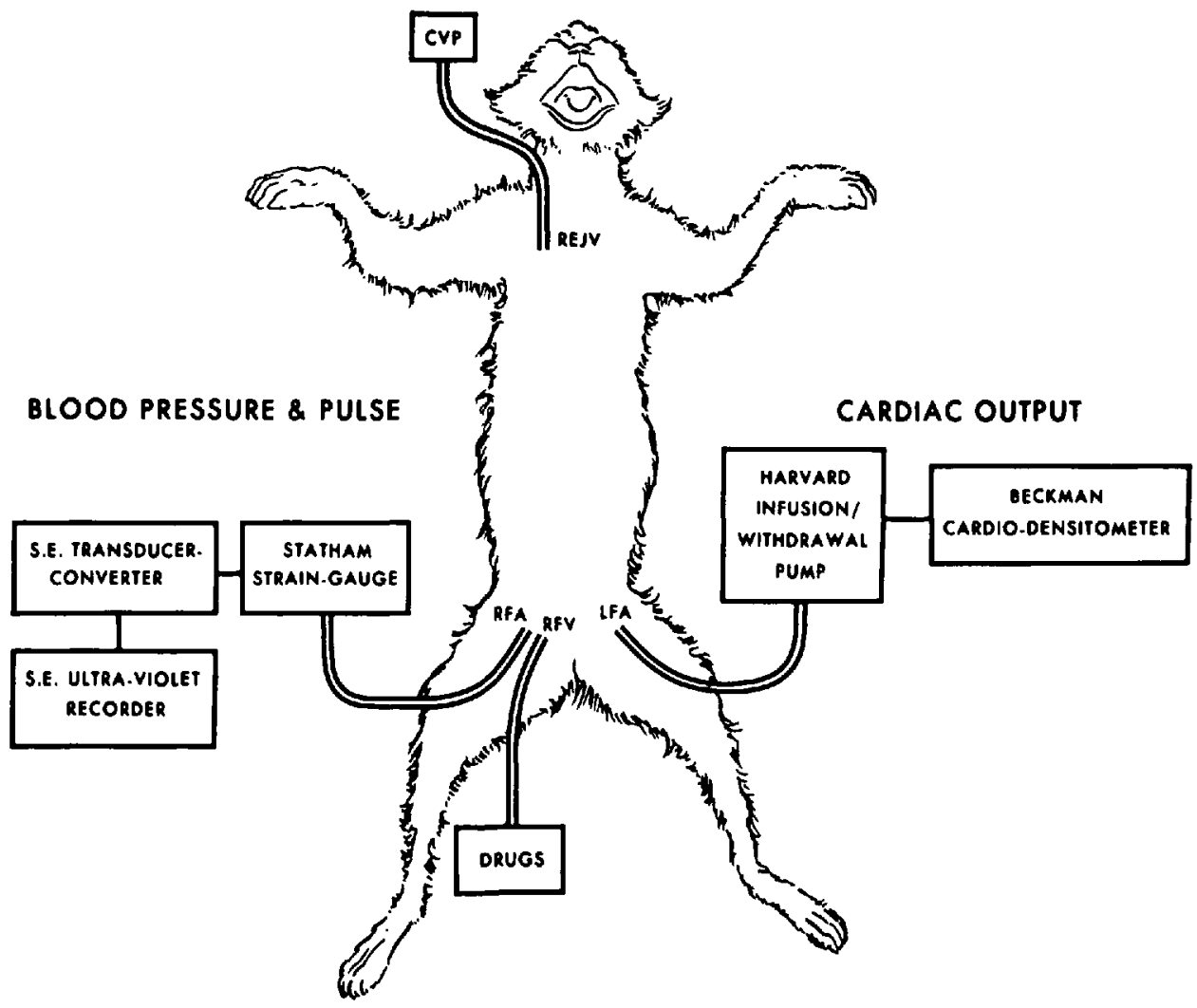

Figure 1. Arrangement of Haemodynamic Monitoring in the Cat Model.

jected into the CVP catheter and washed in with $1 \mathrm{ml}$ of physiological saline through a three-way stop-clock. Blood from the left femoral artery was withdrawn by a Harvard pump and the dye curve was drawn by a Backman Cardiodensitometer (Beckman, Palo Alto, California). 5 to $6 \mathrm{ml}$ of blood was used for each cardiac output measurement, and this was reinfused to the cat after each measurement. Calibration was made at the end of each experiment using four $5 \mathrm{ml}$ blood samples with $0,4,6$, and $8 \mathrm{mg} /$ litre concentration of indocyanine green. The cardiac output was calculated from the area of the dye curve, which was computed by the densiometer's mechanical integrator.

The right femoral vein was also cannulated for the administration of drugs. Apart from the indocyanine green, no drug was injected into the CVP catheter. One dose of heparin, 100 units per $\mathrm{kg}$ body weight, was used to prevent clotting of catheters at the beginning of the experiment.

A control recording of the arterial blood pressure, mean arterial pressure, heart rate and cardiac output was made when the animal was in a steady state, usually about one hour after intubation.

Twenty-five cats were used in this study, and they were divided into four groups as follows: 
1. Control (ten cats).

2. 15 per cent blood volume depletion (five cats).

3. 30 per cent blood volume depletion (five cats).

4. Endotoxin shock ( five cats ).

The first group of ten cats was used to establish the average response following ketamine $5 \mathrm{mg} / \mathrm{kg}$ intravenously. Arterial blood pressure, heart rate and cardiac output were measured before and two minutes after the drug.

For the second and third groups, the blood volume of the cat was taken to be $55.5 \mathrm{ml}$ per kilogram body weight. ${ }^{6}$ A Harvard infusion/withdrawal pump (Model 901 ) was used for withdrawing blood at a rate of $2.47 \mathrm{ml}$ per minute from the left femoral artery. After depletion of the required volume, at least 20 minutes were allowed before the haemodynamic parameters were measured again. When these became stable after the cardiac output measurement, ketamine $5 \mathrm{mg} / \mathrm{kg}$ was injected into the right femoral vein and washed in with $0.5 \mathrm{ml}$ of physiological saline. The haemodynamic parameters were measured again two minutes later.

For the fourth group of cats, a purified endotoxin, Lipopolysaccharide B from E. coli 026:B6 (Difco Laboratories, Detroit, Michigan), was used. The dose required to produce a fairly rapid but not a precipitous fall in arterial blood pressure had previously been determined in other cats. After a $3 \mathrm{mg} / \mathrm{kg}$ dose of this preparation there was usually a lag period of 10 to 15 minutes before the arterial blood pressure started to fall. The fall was quite fast during the following 5 to 10 minutes, and then was maintained at the low level for at least one hour. The arterial blood pressure, heart rate and cardiac output were measured 45 minutes after the endotoxin, and then two minutes after ketamine $5 \mathrm{mg} / \mathrm{kg}$ intravenously.

\section{RESULTS}

\section{Normal Control}

As shown in Table I and Figure 2, ketamine $5 \mathrm{mg} / \mathrm{kg}$ intravenously (IV) raised the cardiac output $25 \pm 8 \%$ and produced no significant change in the heart rate with the technique used.

TABLE I

Cardiovascular Effects of Intravenous Ketamine $(5 \mathrm{mg} / \mathrm{kg}$ ) in Ten Control Cats $(3.3 \pm 0.2 \mathrm{~kg})$. This is Graphically RePresented in Figure 2 . The Values in this and Subsequent Tables are Expressed as Mean \pm Standard Error

\begin{tabular}{lcccc}
\hline \hline & & \multicolumn{3}{c}{ Ketamine 5 mg/kg IV } \\
\cline { 3 - 5 } & Control & Observation & Change & $\mathrm{P}$ \\
\hline $\begin{array}{l}\text { Cardiac Output } \\
\begin{array}{l}\text { Mean Arterial } \\
\text { Blood Pressure }\end{array}\end{array}$ & $472 \pm 64$ & $598 \pm 105$ & $\uparrow 25 \pm 8 \%$ & $\mathrm{P}<0.02$ \\
$\begin{array}{l}\text { Systolic } \\
\text { Arterial BP }\end{array}$ & $117 \pm 5$ & $147 \pm 5$ & $\uparrow 26 \pm 4 \%$ & $\mathrm{P}<0.001$ \\
$\begin{array}{l}\text { Diastolic } \\
\text { Arterial BP }\end{array}$ & $155 \pm 7$ & $195 \pm 10$ & $\uparrow 26 \pm 3 \%$ & $\mathrm{P}<0.001$ \\
$\begin{array}{l}\text { Heart Rate } \\
\text { Heart Ran }\end{array}$ & $99 \pm 4$ & $124 \pm 4$ & $\uparrow 26 \pm 6 \%$ & $\mathrm{P}<0.01$ \\
& $191 \pm 13$ & $204 \pm 14$ & $\uparrow 8 \pm 4 \%$ & not significant \\
\hline
\end{tabular}




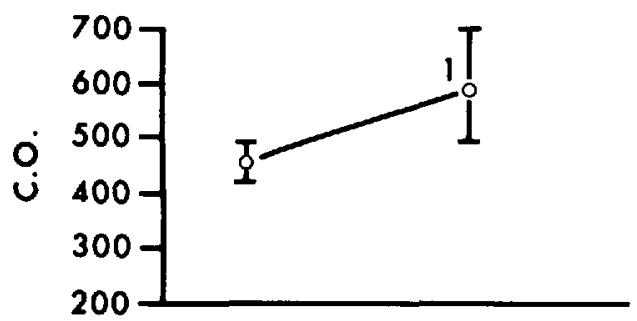

- Cardiac Output or Heart Rate

$\triangle$ Systolic B.P.

- Diastolic B.P.

- Mean B.P.

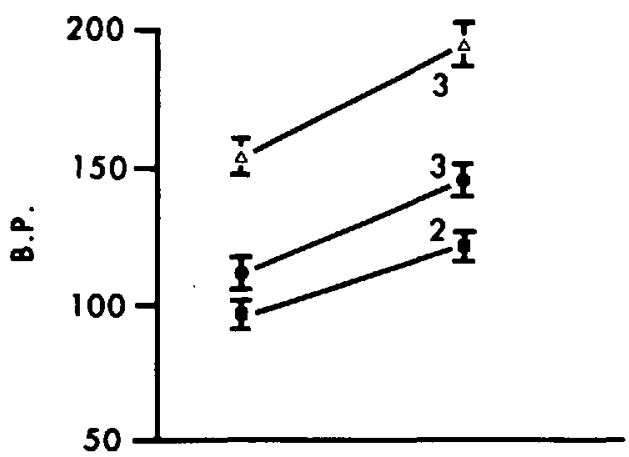

$1 p<0.05$

$2 p<0.01$

$3 p<0.001$

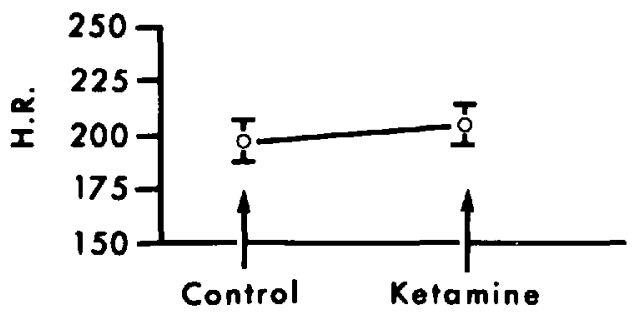

Figure 2. Ketamine ( $5 \mathrm{mg} / \mathrm{kg}$ IV) Control.

\section{Fifteen per cent Blood Volume Depletion}

The results are tabulated in Table II and shown in Figure 3. Fifteen per cent bleeding caused a decrease of $17 \pm 5 \%$ in cardiac output, an increase of $20 \pm 9 \%$ in heart rate and no significant drop in arterial pressure (the mean blood pressure fell $5 \pm 3 \%)$.

Two minutes after intravenous ketamine $(5 \mathrm{mg} / \mathrm{kg})$, there was significant increase of arterial blood pressure - Systolic BP by $12 \pm 2 \%$, and Diastolic BP by $14 \pm 3 \%$. The heart rate was essentially unchanged. The cardiac output likewise showed no significant change.

\section{Thirty per cent Blood Volume Depletion}

The results are shown in Table III and Figure 4. This amount of bleeding produced marked decreases in cardiac output. ( $38 \pm 3 \%)$, systolic BP $(29 \pm 2 \%)$, and diastolic $\mathrm{BP}(37 \pm 4 \%)$, with marked increase in heart rate $(29 \pm 4 \%)$. 

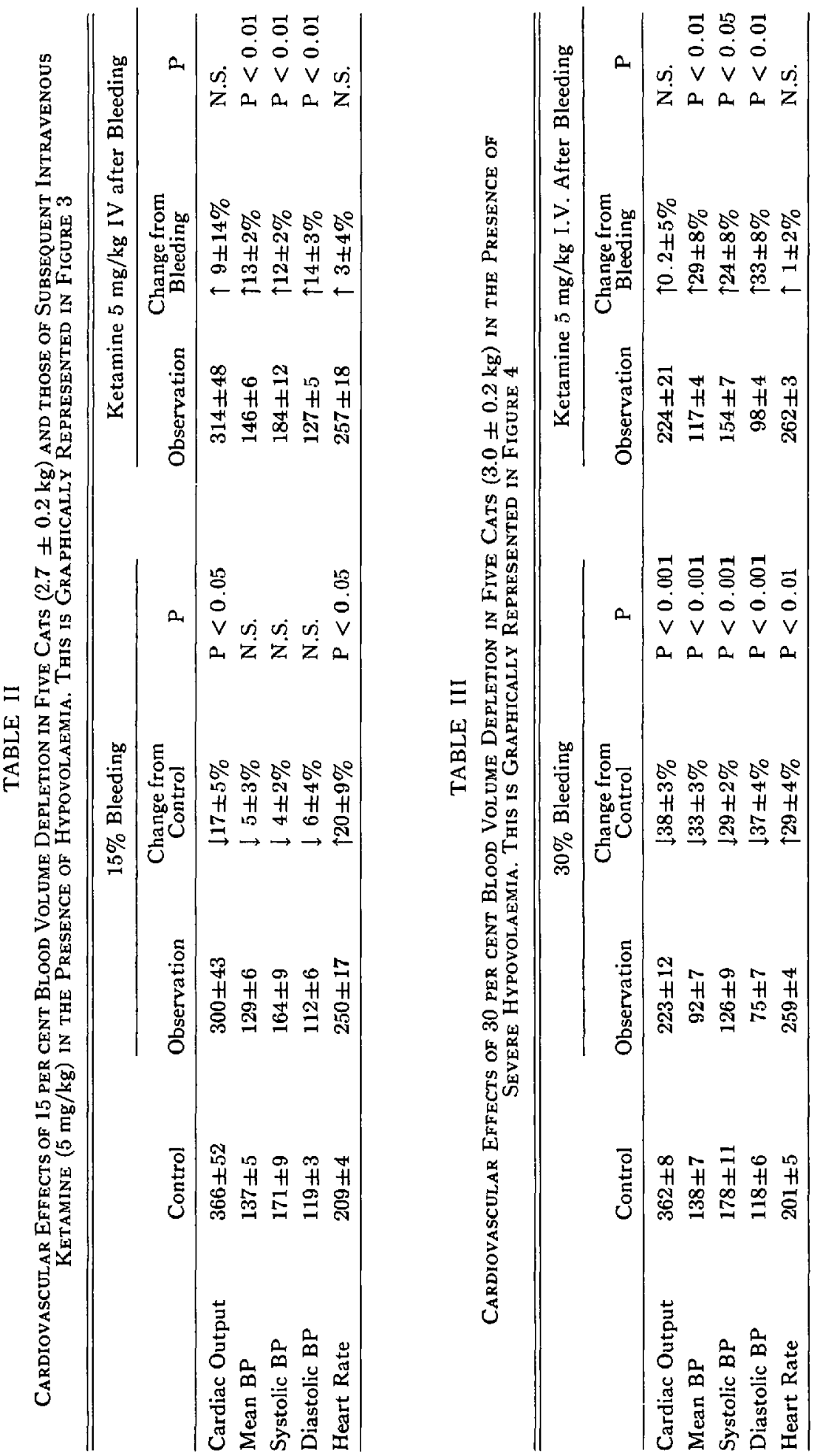


\section{KETAMINE (5 mg/kg I.V.) IN $15 \%$ BLEEDING}

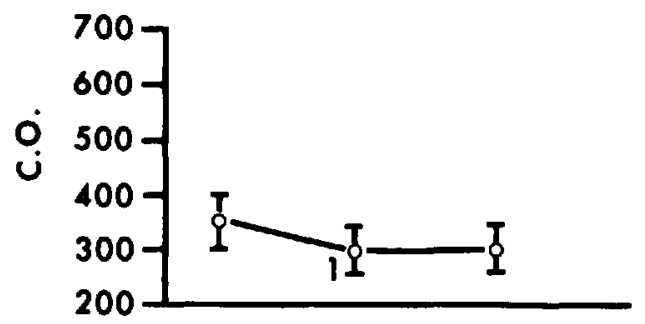
- Cardiac Output
or Heart Rate

$\triangle$ Systolic B.P.

- Diastolic B.P.

- Mean B.P.

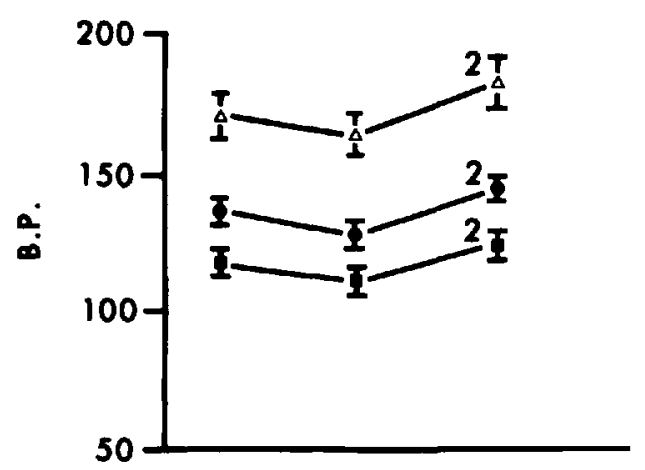

$1 p<0.05$

$2 p<0.01$

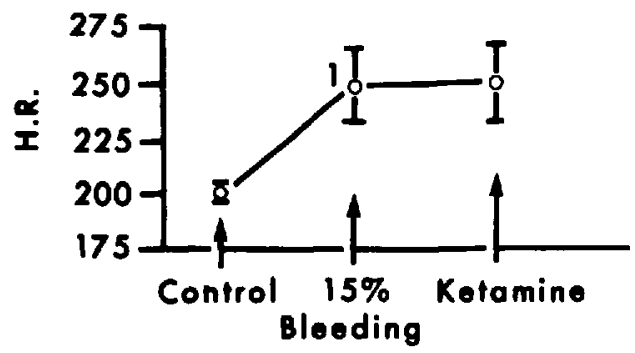

Figure 3. Ketamine ( $5 \mathrm{mg} / \mathrm{kg} \mathrm{IV}$ ) in 15 per cent Bleeding.

Ketamine $5 \mathrm{mg} / \mathrm{kg}$ given intravenously in this situation still raised the arterial BP significantly - systolic by $24 \pm 8 \%$, and diastolic by $33 \pm 8 \%$. Despite the marked increase in blood pressure, the cardiac output remained unchanged.

\section{Endotoxin Shock}

The results are shown in Table IV and Figure 5. With the dose of E. coli endotoxin used, there was marked decrease in cardiac output $(37 \pm 8 \%)$, systolic BP $(33 \pm 6 \%)$ and diastolic $\mathrm{BP}(48 \pm 5 \%)$, and heart rate $(22 \pm 5 \%)$.

Ketamine $5 \mathrm{mg} / \mathrm{kg}$ given intravenously in the presence of this experimentally induced septicaemia returned all these parameters towards, although not quite to, normal. Cardiac output increased $29 \pm 4 \%$, systolic BP $33 \pm 10 \%$, diastolic BP $61 \pm 19 \%$, and heart rate $16 \pm 4 \%$. 
WONG \& JENKINS: CARDIOVASCULAR EFFECTS OF KETAMINE

KETAMINE (5 mg/kg I.V.) IN 30\% BLEEDING
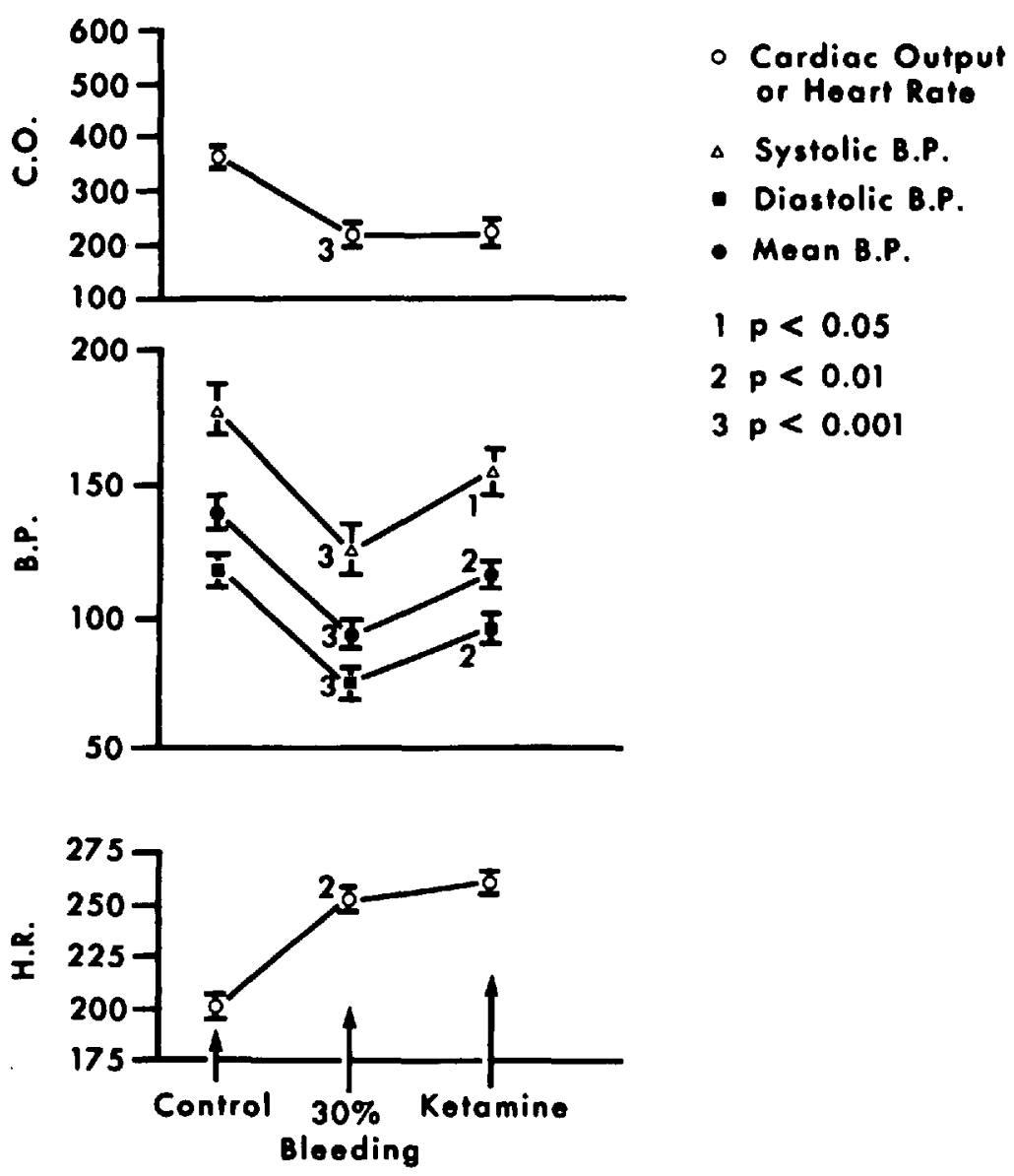

Figune 4. Ketamine $(5 \mathrm{mg} / \mathrm{kg} \mathrm{IV})$ in 30 per cent Bleeding.

\section{Discussion}

The results obtained in group 1 control cats are comparable to those of other workers. ${ }^{7-17}$ The major difference is the lack of significant increase in heart rate after ketamine in the present study. This appears to be due to the already high resting heart rate prior to ketamine administration, because of the light plane of anaesthesia ( $50 \% \mathrm{~N}: \mathrm{O}$ ). Despite a high "resting" sympathetic discharge, there were still significant increases in cardiac output and arterial blood pressure with the use of ketamine.

In both the 15 per cent and 30 per cent blood volume depleted groups, there was significant increase in both the systolic and diastolic arterial blood pressure following intravenous ketamine. However, the cardiac output did not share the same favourable response. This is not unexpected in the presence of circulatory 


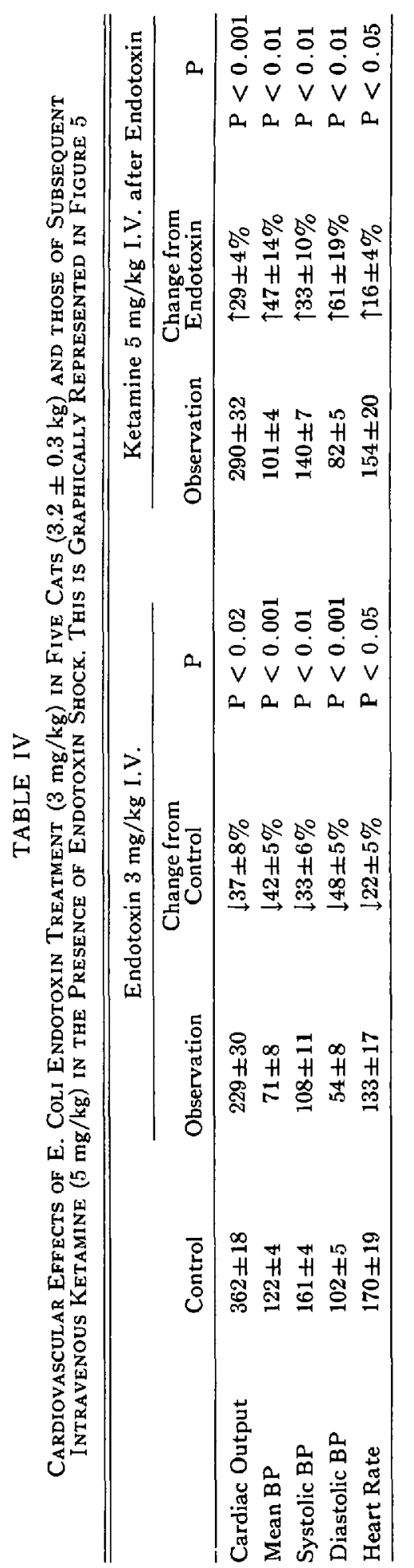


WONG \& JENKINS: CARDIOVASCULAR EFFECTS OF KETAMINE

KETAMINE (5 mg/kg I.V.) IN ENDOTOXIN SHOCK

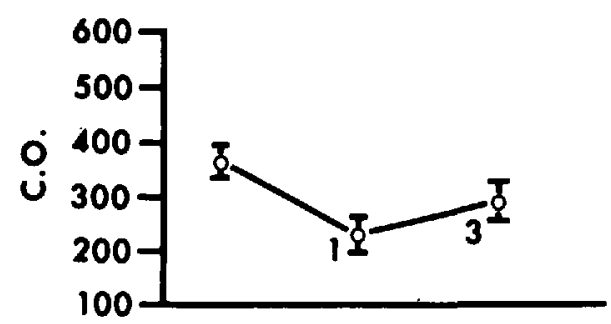

- Cardiac Output or Heart Rate

$\triangle$ Systolic B.P.

- Diastolic B.P.

- Moan B.P.

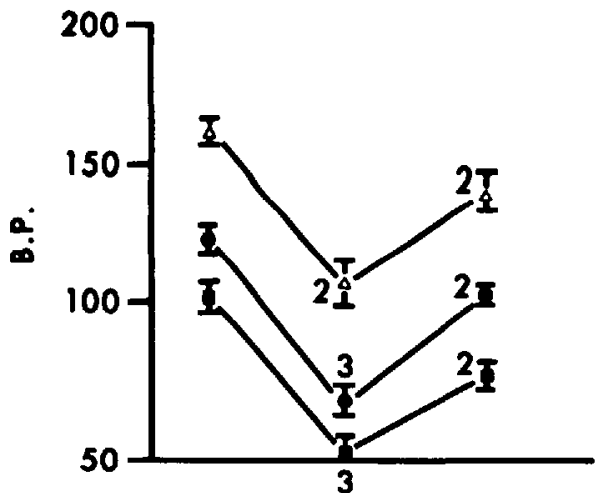

I $p<0.05$

$2 p<0.01$

$3 p<0.001$

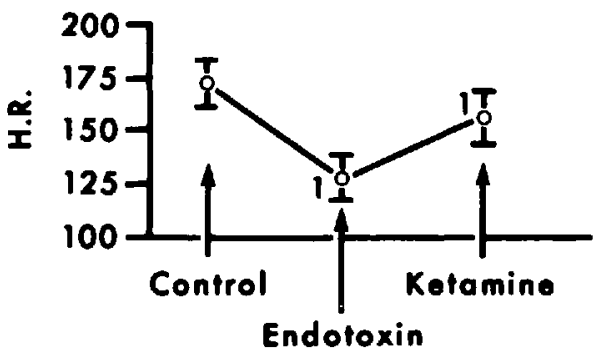

FIgure 5. Ketamine ( $5 \mathrm{mg} / \mathrm{kg} \mathrm{IV}$ ) in Endotoxin Shock.

volume deficit. This brings us to an interesting point. The anaesthetist monitoring the blood pressure and pulse in the operating room would find that ketamine raises the blood pressure in a patient who is in shock from haemorrhage. This merely provides a false sense of security because the cardiac output, and thus the perfusion, is not actually improved. Restoring the circulating volume should still be the primary treatment.

Endotoxin in the dosage used produced significant decrease in cardiac output, arterial blood pressure and heart rate. Ketamine given intravenously in this situation raised all these haemodynamic parameters. The response is quite different from that seen in hypovolaemic states, since in this case cardiac output also improved along with the blood pressure. This would suggest that, in the early stages of septicaemic shock, ketamine might be a useful agent to use if anaesthesia is required. 
Obviously the conditions in which these observations were made were not entirely comparable to clinical situations. The blood volume depletion was deliberately made at a slow and steady rate, and allowance was given to achieve a steady haemodynamic state before measurements were made. This is not the usual clinical situation confronting the anaesthetist. In the endotoxin group, the septic state was of short duration ( 45 to 60 minutes). A large dose of endotoxin was used to produce the desired change and again a steady state was ensured before measurements were made. Certainly caution must be exercised if the results are to be projected to septicaemic states of long duration.

\section{SUMMARY}

Ketamine was found to raise the systemic arterial blood pressure but not necessarily the perfusion in hypovolaemic states. However, in hypotensive states of short duration from endotoxin treatment, it improved the haemodynamics with increase in both the perfusion and the systemic pressure. The implications of these observations for clinical situations were discussed.

\section{RÉSUMÉ}

En mesurant la tension artérielle, la pression veineuse centrale et le débit cardiaque, les auteurs ont démontré que la Kétamine en présence de choc hypovolhémique, élève la tension artérielle sans nécessairement améliorer la perfusion; cependant au cours d'hypotension de courte durée, induite par injection d'endotoxine, la Kétamine améliore et la perfusion et la tension artérielle systémique.

Les applications cliniques de ces constatations sont discutées.

\section{REFERENCES}

1. Conssen, G., Allarde, R., Brosch, F., \& Arbenz, G. Ketamine as the sole anesthetic in open-heart surgery. A preliminary report. Anesthesia and Analgesia (Cleveland), 49: 1025 (1970).

2. Dawson, B., Siker, E.S., \& Wilson, R.D. Would you please summarize the current usefulness of ketamine in anesthetic practice? (Question with Answers), Anesthesia and Analgesia (Cleveland), 50: 1056 (1971).

3. Conssen, G. Ketamine for high-risk cardiac patients. Anesthesiology 36:413 (1972).

4. Abbey, N.D. Ketamine (Letter to the Editor), Canadian Medical Association Journal 106: 749 (1972).

5. Virtue, R.W., Alanis, J.M., Mori, M., Lafarque, R.T., Vogel, J.H.K., \& Metcalf, D.R. An anesthetic agent: 2-orthochlorophenyl, 2-methylamino cyclohexanone $\mathrm{HCl}$ (Cl-581). Anesthesiology 28: 823 (1967).

6. Altman, P.L. \& DitTmer, D.S. (Ed.), Biology Data Book, Federation of American Societies for Experimental Biology, Washington, D.C., p. 264 (1964).

7. Bovill, J.G., Clarke, R.S.J., Davis, E.A., \& Dundell, J.W. Some cardiovascular effects of ketamine in man. British Journal of Pharmacology $41: 411 \mathrm{P}$ (1971).

8. Traber, D.L., Wilson, R.D., \& Priano, L.L. Blockade of the hypertensive response to ketamine. Anesthesia and Analgesia (Cleveland), 49: 420 (1970).

9. WILSON, R.D., Traber, D.L., \& McCoy, N.R. Cardiopulmonary effects of CI-581 - the New Dissociative Anesthetic, Southern Medical Journal 61: 692 (1968). 